\title{
Pull method percutaneous endoscopic gastrostomy using transnasal ultrathin endoscopy in head and neck cancer
}

Dysphagia due to tumor ulcers and stomatitis induced by chemoradiotherapy is painful; it is therefore crucial and urgent to establish a surgical enteral feeding route in patients with head and neck cancer to avoid malnutrition and improve treatment compliance [1]. However, common trismus caused by surgical resection, reconstruction, and, mostly, radiation fibrosis often compromise flexible endoscope passage; furthermore, an oral tumor would raise concern of cancer contamination and inoculation upon percutaneous endoscopic gastrostomy (PEG) $[2,3]$. Herein, we demonstrate the use of an ultrathin endoscope $(5.3 \mathrm{~mm}$ diameter; Olympus VISERA Transnasal Esophagovideoscope, PEF-V; Olympus Medical Systems, Tokyo, Japan), via the transnasal route as a good alternative for better instrument passage in patients with head and neck cancer with trismus or when buccal reconstruction integrity would be a concern.

Patients were placed under transoral or transnasal endotracheal intubation general anesthesia. The transnasal approach would be preferred in patients with an inter-incisor distance of less than two fingers for both endotracheal intubation and PEG. The pull method was our procedure of choice owing to greater control of stomach puncture and less premature extrusion [4,5], and we routinely used a $20 \mathrm{Fr}$ tube (Flow 20 Pull Method; Cook Medical Inc., Bloomington, Indiana, USA) ( Video 1). The puncture site chosen was the most transilluminated area over the gastric antral portion under a dark setting. Our tip to avoid nostril trauma upon passage of the PEG bumper is to squeeze the bumper with one hand while gently pressing the ipsilateral nose alae with the other hand to provide proper counter-support (\$Fig.1). After the PEG procedure, the pressure of the bumper on the gastric mucosa was checked to avoid buried bumper syndrome, and $2-30 \mathrm{~mL}$ distilled water was irrigated

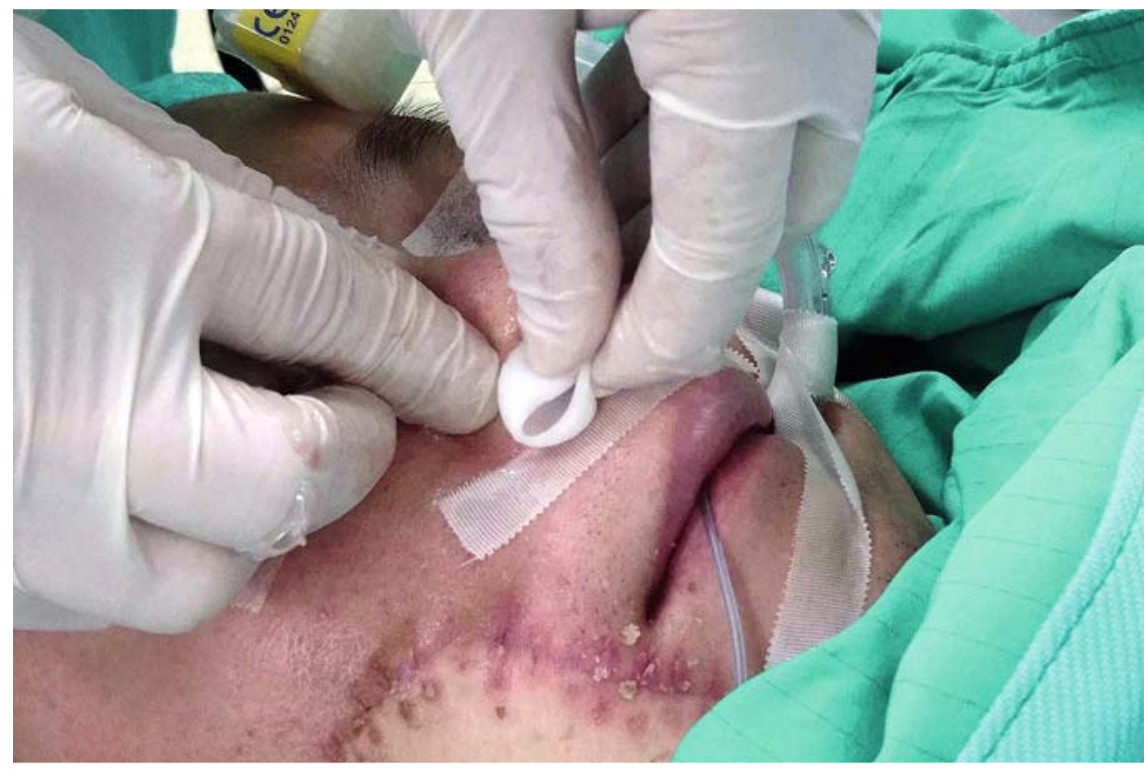

- Fig. 1 Demonstration of our tip to avoid nostril trauma: gentle finger pressure on the ipsilateral nose alae provides proper counter-support, with simultaneous squeezing on the bumper to facilitate passage of the percutaneous endoscopic gastrostomy tube.
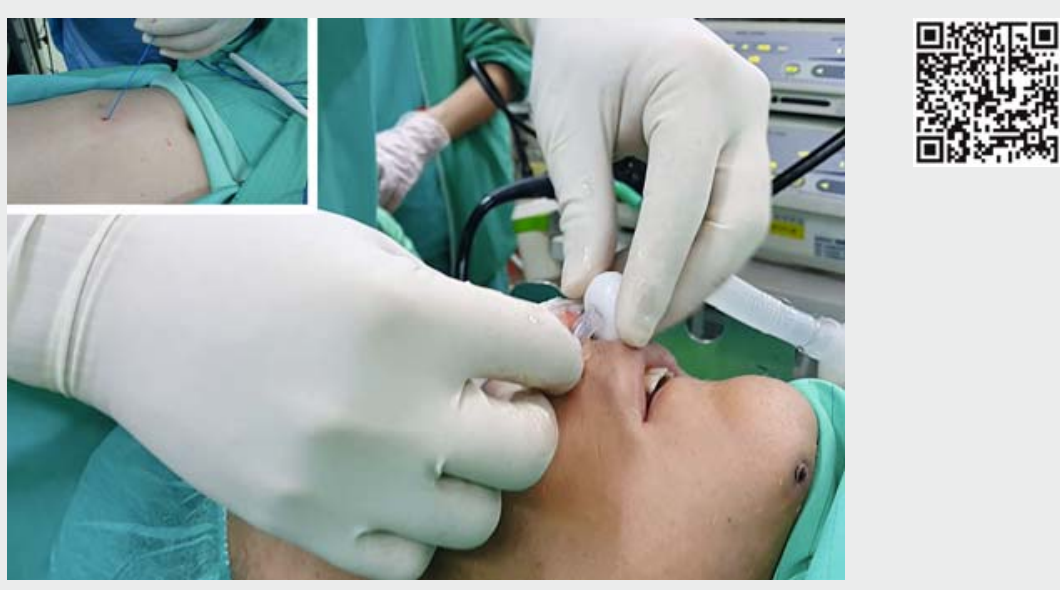

Video 1 Steps in the pull-method transnasal ultrathin endoscopy for percutaneous endoscopic gastrostomy (PEG). (i) Confirmation of successful passage of a $5.3 \mathrm{~mm}$ endoscope. (ii) Inflation of the stomach and localization of the puncture site at the most transilluminated area. (iii) Puncture and insertion of the guidewire. (iv) Pulling the PEG tube via the transnasal route. (v) Irrigation with distilled water, and checking the pressure of the PEG bumper against the gastric wall. 
over the mucosa in contact with the bumper to prevent tumor inoculation.

We have not encountered nasal bleeding in our series of 20 cases. Our experience showed that PEG using a transnasal ultrathin endoscope could be a good alternative approach when the transoral route is compromised, especially in cases of head and neck cancer.

Endoscopy_UCTN_Code_TTT_1AO_2AK

Competing interests

None

The Authors

jia-Ming Chang 1,2,3, Yi-Ting Yen 2,4, Chao-Chun Chang ${ }^{4}$, Yau-Lin Tseng ${ }^{4}$, Wu-Wei Lai ${ }^{4, ~ *, ~}$ Kam-Hong Kam ${ }^{1, *}$

1 Division of Thoracic Surgery, Department of Surgery, Chia-Yi Christian Hospital, Chia-Yi, Taiwan

2 Institute of Clinical Medicine, National Cheng Kung University, Tainan, Taiwan

3 Graduate Institute of Medical Sciences, College of Health Science, Chang Jung Christian University, Tainan, Taiwan

4 Division of Thoracic Surgery, Department of Surgery, National Cheng Kung University Hospital, Tainan, Taiwan

* These authors contributed equally to this work.
Corresponding author

\section{Kam-Hong Kam, MD}

Division of Thoracic Surgery, Department of Surgery, Chia-Yi Christian Hospital, 539 Jhongsiao Road, Chia-Yi 600, Taiwan Fax: +886-5-2774511

hongsurgeon@gmail.com

\section{References}

[1] Findlay M. Bauer J. Brown T, Committee HaNGS. Evidence based practice guidelines for the nutritional management of adult patients with head and neck cancer. Sydney: Cancer Council Australia; 2014

[2] Cappell MS. Risk factors and risk reduction of malignant seeding of the percutaneous endoscopic gastrostomy track from pharyngoesophageal malignancy: a review of all 44 known reported cases. Am J Gastroenterol 2007; 102: 1307-1311

[3] Huang AT, Georgolios A, Espino S et al. Percutaneous endoscopic gastrostomy site metastasis from head and neck squamous cell carcinoma: case series and literature review. J Otolaryngol Head Neck Surg 2013; 42: 20

[4] Iman NU, Khan H, Khan HU. Percutaneous endoscopic gastrostomy. Gomal Journal of Medical Sciences 2008; 6: 124-130

[5] Rahnemai-Azar AA, Rahnemaiazar AA, Naghshizadian R et al. Percutaneous endoscopic gastrostomy: indications, technique, complications and management. World J Gastroenterol 2014; 20: 7739-7751

\section{Bibliography}

DOI https://doi.org/10.1055/s-0043-111709

Published online: 14.6.2017

Endoscopy 2017; 49: E188-E189

(c) Georg Thieme Verlag KG

Stuttgart · New York

ISSN 0013-726X

\section{ENDOSCOPY E-VIDEOS}

https://eref.thieme.de/e-videos

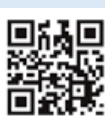

Endoscopy E-Videos is a free access online section, reporting on interesting cases and new

techniques in gastroenterological endoscopy. All papers include a high quality video and all contributions are freely accessible online.

This section has its own submission website at https://mc.manuscriptcentral.com/e-videos 